\title{
Effect of Silicon Carbide on the Mechanical and Thermal Properties of Snake Grass/Sisal Fiber Reinforced Hybrid Epoxy Composites
}

\author{
Vijayakumar $\mathrm{M}^{1^{*}}$, Kumaresan $\mathrm{K}^{2}$, Gopal $\mathrm{R}^{3}$, Vetrivel $\mathrm{S} \mathrm{D}^{4}$ and Vijayan $\mathrm{V}^{5}$ \\ ${ }^{1}$ Department of Mechanical Engineering, JCT college of Engineering and Technology, Coimbatore, Tamilnadu, India \\ ${ }^{2}$ Department of Mechanical Engineering, Park College of Engineering and Technology, Coimbatore, Tamilnadu, India \\ ${ }^{3}$ Department of Mechanical Engineering, Trichy Engineering College, Trichy, Tamilnadu, India \\ ${ }^{4}$ Department of Robotics and Automation Engineering, PSG College of Technology, Coimbatore 641004, Tamil Nadu, India \\ ${ }^{5}$ Department of Mechanical Engineering, K.Ramakrishnan College of Technology, Trichy, Tamil Nadu, India
}

\begin{abstract}
Corresponding Author Email: mechmvijay@gmail.com
ABSTRACT

In this study, an attempt was made to develop and characterize Snake Grass Fiber (SGF)/Silicon Carbide (SiC)/epoxy and Snake Grass Fiber/Sisal Fiber (SF)/Silicon Carbidelepoxy hybrid composites using a compression moulding technique. Mechanical characteristics of the produced hybrid composites such as tensile, flexural, and hardness tests were analyzed. Also experiments have been carried out to predict the thermal stability of the fabricated composite samples. The interface between fiber and matrix was examined by using Scanning Electron Microscopy (SEM). Among SGF/SiC/epoxy and SGF/SF/SiClepoxy composites, it has been observed that hybrid composite SGF/SF/SiClepoxy exhibits the higher hardness of 82 Shore-D, tensile strength of $51 \mathrm{MPa}$ and flexural strength of $73 \mathrm{MPa}$. In contrast to the mechanical properties, the percentage of water absorption was lower in the SGF/SiClepoxy hybrid composite. It is proven from the results that the $S G F / S F / S i C l e p o x y$ hybrid composites will enhance the strength of the composites. This composite material is also a potential candidate for the hardware of energy devices including electrochemical energy along with Fuel Cell systems.
\end{abstract}

Keywords: hybrid composite, snake grass fiber, sisal fiber, SiC, mechanical properties, water absorption, thermal properties Received: January-25-2021, Accepted: April-15-2021, https://doi.org/10.14447/jnmes.v24i2.a09

\section{INTRODUCTION}

Natural fiber reinforced polymer composites have attracted considerable interests especially in automotive, energy, including electrochemical energy hardware devices construction and furniture applications. The Natural fibers are low density, high strength, biodegradability and lightweight fibers which are extracted from plants, suitable for fabricating low cost, non-toxicity, high strength to weight ratio and good wear resistance polymer Composites [1].

Sathiskumar et al. [2] extracted the snake grass fiber, tested its properties like density, diameter, tensile strength and $\%$ elongation. Also prepared the composites with snake fiber reinforcement and isophthalic unsaturated polyester resin for different volume fractions. They reported that the $25 \%$ volume fraction composite exhibited the highest tensile strength and flexural strength. Ganeshan et al. [3] investigated the effect of fiber length and fiber content on the mechanical properties in the madar fiber reinforced polyster composites. It is found that Mechanical properties increase with the increase in fiber length $(5 \mathrm{~mm}$ to $10 \mathrm{~mm})$ and fiber $\mathrm{wt} \%$ (20 to 25). Likewise Higher madar fiberwt \% composites strength decreased with the increased in fiber length $(15 \mathrm{~mm}$ and 20 $\mathrm{mm}$ ). de Andrade Silva et al. [4] studied the tensile strength of the sisal fiber reinforced FRP composite with different fiber length and concluded that short length of the fiber imparts notable tensile strength in the composite. Sathish et al. [5] prepared the hybrid composites of different volume fractions using flax and bamboo fibers and epoxy resin by compression molding technique. They reported that the tensile and flexural strength was high for the sample contains $30 \%$ bamboo fiber.

However, proper fiber surface treatment is required to improve the interface between the fibers and matrix. Various methods used are Acetylation treatment, alkaline treatment, Benzoylation, furfuryl alcohol (FA) treatment, Peroxide treatment and Permanganate treatment. Alkaline, heat and coupling agent treatments are necessary to overcome the poor interfacial bonding between sisal fiber and the matrix [6]. Bakare et al. [7] analyzed the water treated and untreated sisal fiber reinforced polyurethane composite for its mechanical behavior. Li et al. [8] investigated the adhesion behavior between sisal fiber and the matrix by using Silane and KMnO4 treated sisal fiber reinforced to high density polyethylene (HDPE) composites. Because of the hydrophilic nature of cellulose and the hydrophobic properties of HDPE the interaction between sisal fibers and the HDPE matrix was poor. But $\mathrm{KMnO} 4$ surface treatment method is more helpful in adhesion bonding between fibers and the HDPE resin. Proper selection of fibers, epoxy resin and surface treatments of the natural fibers plays an important role in fiber reinforced polymer based composites. Rong et al. [9] studied the effect of various chemically treated sisal fibers in the epoxy composites to predict the relationship between mechanical properties and adhesion property. It is found that achieved higher fiber stiffness and the adhesion between fiber bundles. Also the matrix has increased flexural strength. Sathiskumar et al. [10] studied the influences of two different combinations natural fibers in the hybrid polymer matrix.

Hybrid composites are reinforced with snake grass/banana fibers and snake grass/coir fibers fabricated to compare its 
tensile and flexural results with the composites reinforced with snake grass fiber alone. Addition of another natural fiber increases the mechanical properties of composites. In addition to the type of matrix used, the treatment of fiber, incorporation of various fillers and hybridization also has a significant impact on the mechanical properties sisal fiber reinforced polymer composites, improved interfacial bonding between fiber and matrix this leads to better mechanical interlocking with the polymer matrix [11]. Ganapathy et al. [12] introduced graphene powder in the banyan aerial root fibers reinforced epoxy composites. The authors reported that Mechanical properties such as tensile, flexural, hardness and water absorption behavior of the modified composites are improved by increasing the $\mathrm{wt} \%$ of graphene. Sathish et al. [13] studied the addition of $\mathrm{SiC}$ filler powder in the epoxy matrix improved the mechanical properties and also $5 \% \mathrm{NaOH}$ treatment highly influenced in the interfacial bonding between fiber and resin. Added $\mathrm{SiC}$ nano filler reinforced composites showed significant improvement in both mechanical and thermal properties.

Nhuapeng et al. [14] investigated the mechanical and tribological properties of silicon carbide nano particles and nanowires/nanowhisker reinforced epoxy composites. The authors found that the tensile and flexural strength of the $\mathrm{SiC} /$ epoxy composites initially improved with the increasing content of $\mathrm{SiC}$ nanowires, but decreased with excessive addition of SiC. Hardness properties of samples do not relate to the filler shape used in the matrix. But it affects the wear rate due to the effect of spherical shape on sliding and ball bearing. SiC nanoparticles showed the better wear rate than the SiC nano whiskers. Ramprabu et al. [15] resulted that the thermal degradation of sisal fiber starts above $200^{\circ} \mathrm{C}$. The porous structure of the fiber degrades the thermal behavior at elevated temperature. Chemical treatment and addition of glass fiber increases the thermal characteristics of the composites. According to George and Verpoest [16] the sisal fiber absorbs water due to its hydrophilic nature and the loss of absorbed water interrupts the thermogram at $40^{\circ} \mathrm{C}-50^{\circ} \mathrm{C}$. This phenomenon was found in the fibers which contains $\mathrm{O}-\mathrm{H}$ functional groups. The negligible amount of mass percentage of fiber was observed in the range of $60^{\circ} \mathrm{C}-300^{\circ} \mathrm{C}$ due to the lower rate of degradation of fiber at this temperature range. As Van de Velde and Beatens [17] reported, after $300^{\circ} \mathrm{C}$, the degradation of lignin, cellulose, and hemicelluloses present in the fiber was more rapid and major weight loss was observed. Loganathan et al. and Loganathan et al. [18, 19] said that percentage variations of Chicken feather fibre have an important effect on the tensile strength as well as the yield strength from the experimental tensile and yield strength analysis research on composites of pure jute fibre with Chicken feather fibre. Sreekumar et al. [20] investigated the thermal behavior of treated and untreated sisal fiber reinforced polyester composites. Treated fiber reinforced composites were found to be thermally more stable than untreated derivatives and Moisture absorption also decreased in treated fiber composites. Chemical treatments not only improve the adhesion between fiber and the matrix, it helps to improve the thermal stability. In addition to improving adhesion between the fiber and the matrix, chemical treatments improve thermal stability.

From the literature study it is obvious that only few authors have done work on combination of sisal fiber, snake grass fiber, SiC particle reinforced epoxy hybrid composites. By varying the weight percentage of snake grass and sisal fibers (40 wt $\%$ as maximum) and $\mathrm{SiC}$ particles used as filler introduced in the epoxy resin (60 $\mathrm{wt} \%$ constant for all composites) to fabricate hybrid composites. The main objective of the study is to determine the mechanical properties, water absorption behavior and thermal behavior of the modified epoxy composites.

\section{EXPERIMENTATION}

\subsection{Materials}

The Snake Grass (SGF) fiber is a newly identified fiber from the southern part of India and is extracted by simple water retting process. These grasses are plucked from soil and rinsed with water to remove the sand. The stamp (external green layer) was removed by hand and to remove the external layer of the fiber by biodegradation, it was soaked in water for 24 hours. Then it was dried in the sun light. Now, the fiber was extracted from the grass as a continuous strand. To improve the adhesion property of fiber with matrix, it is necessary to reduce the hydrophilic nature of the fiber which is possible by chemical treatment. The clean dried fiber was soaked for 5 hours in $5 \% \mathrm{NaOH}$ solution (10 liters of water with 50 grams of $\mathrm{NaOH}$ ). Later, it was taken out from the solution and rinsed well in running water and dried in sun light for 24 hours. Then it is treated in oven at $60^{\circ} \mathrm{C}$ for 5 hours. Now, chemically treated fiber as shown in the Figure 1 (a) is ready to make composite. Finally the fibers were cut in to $28 \mathrm{~cm}$ length.

Sisal Fiber (SF) is categorized as a hard fiber and its plants are cultivated mainly in India, Indonesia, Brazil, and east Africa. From $2^{\text {nd }}$ year onwards a plant can give the fibers for the period of up to twelve years, then the plant have 120 to 140 leaves and each leaves contain around 1000 fibers. Sisal fiber shown in Figure 1 (b) is extracted and treated chemically by same procedure as mentioned for snake grass fiber. Chemical properties of the snake grass and sisal fiber are listed in the Table 1.

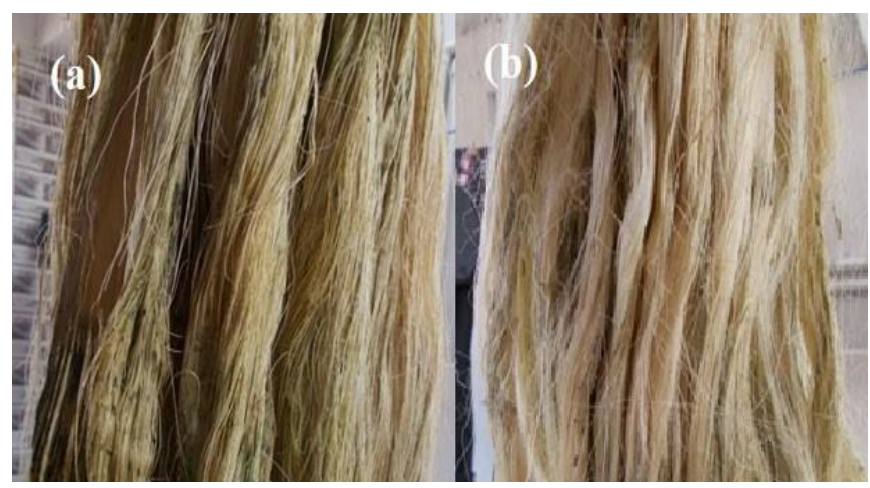

Figure 1. Natural fibers (a) Snake Grass Fiber (b) Sisal fiber

Commercially available Silicon carbide (SiC) was added in the matrix in a powder form with the particle size of 35 to 80 $\mu \mathrm{m}$ obtained from Coimbatore metal mart, Coimbatore, India. The epoxy resin (LY556) and Aradur (HY 951) are used as matrix and catalyst (were procured from Coimbatore metal mart, Coimbatore, India). It is an unmodified biphenyl as a medium viscosity based resin. This epoxy resin is not reacted with chemicals and has better mechanical characteristics, excellent adhesion properties, low shrinkage nature and good heat resistance. 
Table 1. Chemical properties of fibers

\begin{tabular}{cccc}
\hline $\begin{array}{c}\text { Sl. } \\
\text { No. }\end{array}$ & Property & $\begin{array}{c}\text { Snake Grass } \\
\text { (SGF) } \\
\text { Fiber }\end{array}$ & $\begin{array}{c}\text { Sisal } \\
\text { Fiber } \\
\text { (SF) }\end{array}$ \\
\hline 1 & Cellulous content (\%) & $65-75$ & $65-68$ \\
2 & Lignin content (\%) & 5.84 & $9.9-14$ \\
3 & Hemicelluloses (or) pentosan & 11.5 & $10-22$ \\
4 & (\%) & 10.25 & $10-22$ \\
\hline
\end{tabular}

\subsection{Fabrication of composite material}

In this study the hybrid composites are prepared by compression moulding technique. The treated fibers were randomly oriented in a metal die of $280 \times 200 \times 4 \mathrm{~mm}^{3}$. Figure 2 explains the Step-by step procedure of composite fabrication. Initially the mold was cleaned and coated with polishing wax for easy removal of composites from mould. The dried fibers are randomly arranged in the mould by manually. Silicon powders $(\mathrm{SiC})$ poured into epoxy resin/catalyst and stirred mechanically for 25 mins to get uniform mixing of the $\mathrm{SiC}$ powders in the matrix. Epoxy mixer with $\mathrm{SiC}$ was poured onto the fibers and the mould was closed for compression. Then the mold placed on the hydraulic press, and it was compressed with the applying compressive pressure of 5 bars, allowed resin to cure for 24 hours in the atmospheric temperature. Fabricated composite plate was obtained from the mold after solidification, and then it was post-cured for 1 hour in the oven with the constant temperature setting of $60^{\circ} \mathrm{C}$. Composite samples prepared without addition of SiC powders, named as A1 and B1. Composite samples A2 to A6 are prepared by varied snake grass fiber and $\mathrm{SiC}$ percentage. Similarly Composite samples B2 to B6 are prepared by added sisal fiber additionally with SGF and $\mathrm{SiC}$ are shown in Figure 3. From Table 2 shows the weight percentage and properties of the composite materials.

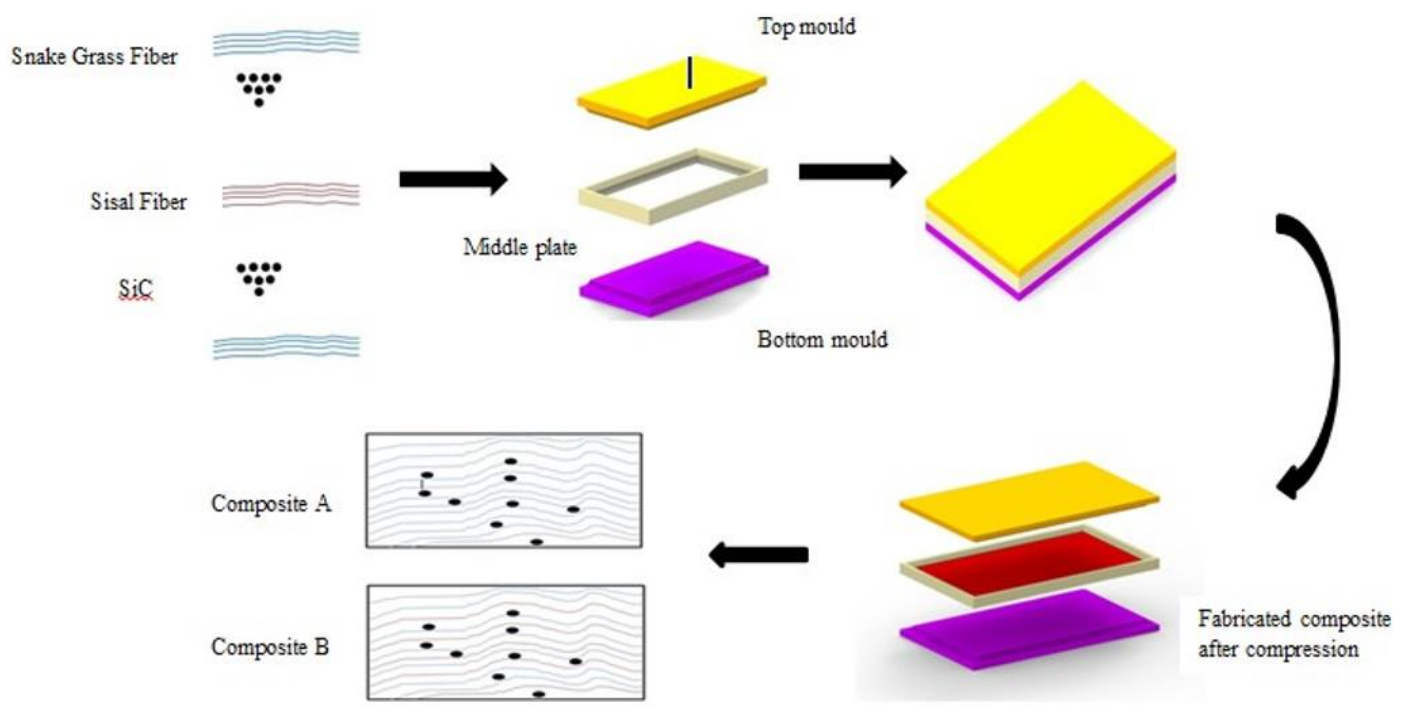

Figure 2. Fabricating procedures of the composite samples
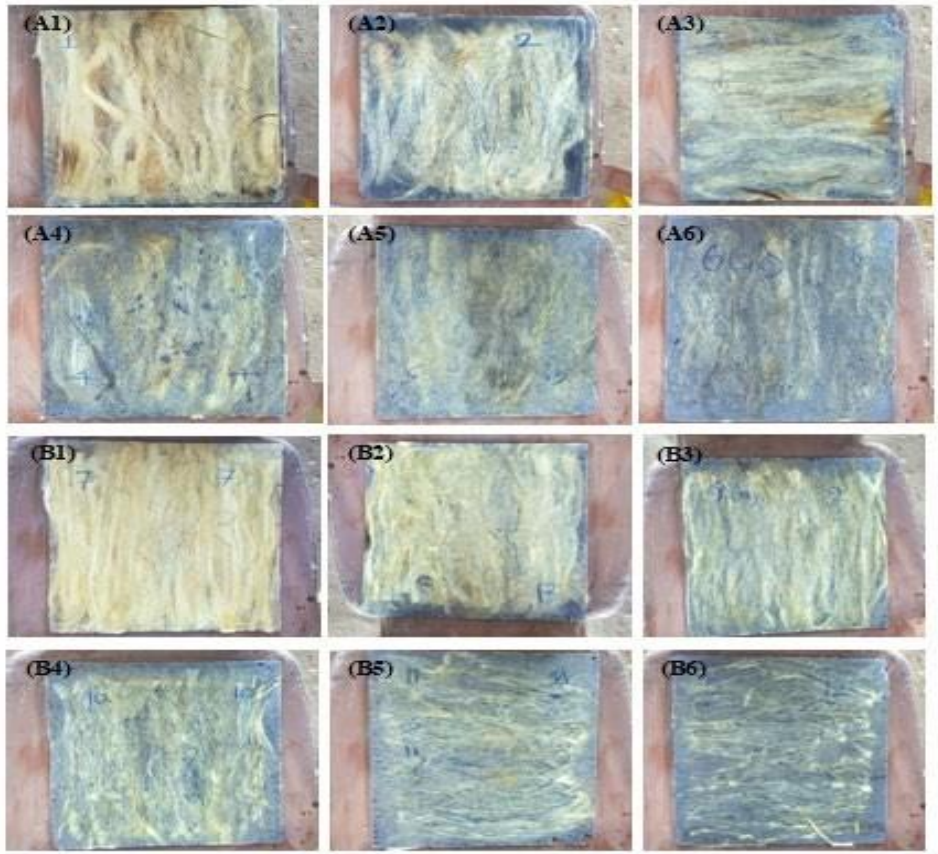

Figure 3. Fabricated composite samples 
Table 2. Weight percentage of reinforcements in the composites

\begin{tabular}{|c|c|c|c|c|}
\hline \multicolumn{5}{|c|}{ SampleResin (wt $\%) \mathrm{SiC}(\mathrm{wt} \%) \underset{\text { Fiber (wt } \%)}{\text { Snake grass }}$ Sisal fiber (wt $\%$} \\
\hline A1 & 60 & 0 & 40 & - \\
\hline A2 & 60 & 2 & 38 & - \\
\hline A3 & 60 & 4 & 36 & - \\
\hline A4 & 60 & 6 & 34 & - \\
\hline A5 & 60 & 8 & 32 & - \\
\hline A6 & 60 & 10 & 30 & - \\
\hline B1 & 60 & 0 & 20 & 20 \\
\hline B2 & 60 & 2 & 19 & 19 \\
\hline B3 & 60 & 4 & 18 & 18 \\
\hline B4 & 60 & 6 & 17 & 17 \\
\hline B5 & 60 & 8 & 16 & 16 \\
\hline B6 & 60 & 10 & 15 & 15 \\
\hline
\end{tabular}

\subsection{Characterization}

\subsubsection{Mechanical properties-tensile test}

The fabricated hybrid composite material was cut into the required dimension by using of saw cutter for tensile test and the edges of the testing specimens are finished by using of emery paper. For the Tensile Test the dimensions and gauge length of the testing specimen, and cross- head speed of the Universal Testing Machine (UTM) are chosen according to the ASTM D638 standard. The test specimen was prepared with length of $250 \mathrm{~mm}$, width of $25 \mathrm{~mm}$ and thickness of $3 \mathrm{~mm}$ as per ASTM D638 standard. Load cell of $500 \mathrm{~N}$ and the tensile force was applied by the cross head at the rate of $20 \mathrm{~mm} / \mathrm{min}$ until the sample fractures.

\subsubsection{Shore hardness test}

Shore D hardness gives measure of resistance to the indentation. Specimen with the dimension $60 \mathrm{~mm} \times 12 \mathrm{~mm} \times$ $3 \mathrm{~mm}$ was cut from each composite plate to carryout hardness measurement. It was done as per the ASTM D2240 standard. The durometer device was used to measure the shore hardness with D scale.

\subsubsection{Flexural test}

The flexural test specimens are prepared as per ASTM D790 standard. This test also was done in a computerized universal testing machine (UTM). The load cell used was $500 \mathrm{~N}$ and a crosshead speed of $10 \mathrm{~mm} / \mathrm{min}$ was used for the test.

\subsubsection{Water absorption test}

The water absorption test was carried according to the ASTM D 570 standard. The specimen size of the samples used for testing is $64 \times 12.7 \times 3 \mathrm{~mm}$. The distilled water was used to find the water absorption behavior of the composites.

The percentage of water absorption in the composites is calculated using given equation below.

$$
\frac{\text { Water absorption }=\text { Wet Weight }- \text { Dry Weight } \times 100}{\text { Dry weight }}
$$

\subsection{Surface morphology}

\subsubsection{Microstructure and EDX analysis}

Surface morphology of fabricated composites reinforced with natural fibers (sisal and snake grass fiber) and $\mathrm{SiC}$ powder were analyzed using CARL ZEISS model V18 scanning electron microscope. The samples were sputter coated with gold and placed on the stub using conductive silver paint prior to get the image. Additionally Energy desperative x-ray analysis was done on both samples and the spectra were analyzed.

\subsubsection{Fourier transform infrared spectroscopy}

The interaction between fibers and matrix material was determined by Fourier transform infrared (FTIR) spectroscopy analysis. For this, $\mathrm{KBr}$ disk samples were prepared by mixing fiber with $\mathrm{KBr}$ in a defined ratio and the pellets were formed by pressing this mixer under vacuum. The IR spectra were recorded with $4 \mathrm{~cm}^{-1}$ resolution in the range of $40^{\circ} \mathrm{Cm}^{-1}$ to $4000 \mathrm{~cm}^{-1}$ and 20 scans per specimen in transmittance mode.

\subsection{Thermal property analysis}

2.5.1 Thermogravimetric analysis (TGA) and differential scanning calorimeter (DSC)

Thermo gravimetric analysis (TGA) and Differential scanning calorimetry (DSC) test was conducted on NETZSCH STA 449F3-1100-M instrument. The powdered sample of weight $10 \mathrm{mg}$ was placed in aluminum crucible to eliminate the variation of temperature measured by the thermo couple. The temperature range of $30^{\circ} \mathrm{C}$ to $550^{\circ} \mathrm{C}$ with a heating rate of $10^{\circ} \mathrm{C}$ per minute was used for testing in nitrogen atmosphere with the flow rate of $20 \mathrm{ml}$ per minute and the same procedure was followed by Martin et al. [21].

\section{RESULT AND DISCUSSION}

\subsection{Tensile strength analysis}

Table 3. Mechanical properties of composites

\begin{tabular}{ccccc}
\hline $\begin{array}{c}\text { Composite } \\
\text { no }\end{array}$ & $\begin{array}{c}\text { Tensile } \\
\text { Strength } \\
\text { (MPa) }\end{array}$ & $\begin{array}{c}\text { Flexural } \\
\text { Strength } \\
\text { (MPa) }\end{array}$ & $\begin{array}{c}\text { Shore D } \\
\text { Hardness }\end{array}$ & $\begin{array}{c}\text { Percentage of } \\
\text { water } \\
\text { absorption }\end{array}$ \\
\hline A1 & 25.02 & 53.33 & 68 & 17.71 \\
A2 & 23.04 & 50.516 & 73 & 14.65 \\
A3 & 27.82 & 43.80 & 76 & 10.59 \\
A4 & 23.00 & 52.74 & 68 & 8.75 \\
A5 & 22.69 & 44.91 & 79 & 7.21 \\
A6 & 15.21 & 44.28 & 76 & 5.47 \\
B1 & 35.72 & 71.17 & 70 & 15.27 \\
B2 & 32.16 & 55.63 & 76 & 13.02 \\
B3 & 41.9 & 55.24 & 77 & 12.33 \\
B4 & 28.76 & 56.26 & 74 & 9.29 \\
B5 & 24.46 & 46.36 & 79 & 6.82 \\
B6 & 24.06 & 43.69 & 81 & 10.81 \\
\hline
\end{tabular}

The mechanical properties of composites from both groups are presented in Table 3 . The tensile strength of composites in group $\mathrm{A}$ is increasing with the $\mathrm{SiC}$ initially up to $6 \%$. It may due to the improvement in adhesion properties $\mathrm{SiC}$ with fibers and resin. But, addition of $\mathrm{SiC} 9 \%$ and above, the strength is decreased. This may be due to the reduction of fiber content in the composite. Similarly, the samples of group B also recorded the same pattern of change in tensile strength. Also, the tensile strength of composites in group B is higher for all the combinations when compared to the tensile strength of the composites in group A. It indicates that the additionally added sisal fiber imparts good strength to the fiber. The highest 
tensile strength recorded at $4 \%$ of $\mathrm{SiC}$ is $27.82 \mathrm{MPa}$ in group A and $41.9 \mathrm{MPa}$ in group B. It is obvious that the tensile strength is increased by the sisal fiber. However, the improvement of mechanical properties depends strictly on the weight percent used, so there is a critical weight percent above which the mechanical properties decrease.

\subsection{Shore D hardness}

The hardness of each samples in both groups are presented in Figure $4 \& 5$. Shore D hardness is increasing with increased $\mathrm{SiC} \mathrm{wt} \%$. It is due to the enhancement of bonding property of $\mathrm{SiC}$ with fiber and resin. Normally, without $\mathrm{SiC}$, the hardness of the samples was recorded as 68 and 70 for $40 \mathrm{wt} \%$ of snake grass fibers in A1 composite and combination of snake grass $20 \mathrm{wt} \%$ and sisal fiber $20 \mathrm{wt} \%$ in B1 composite. Maximum of shore D hardness of 79 was obtained with $8 \mathrm{wt} \%$ of $\mathrm{SiC}$ from group A and hardness of 81 was obtained in the sample of 10 $\mathrm{wt} \%$ of $\mathrm{SiC}$ from group $\mathrm{B}$ composites.

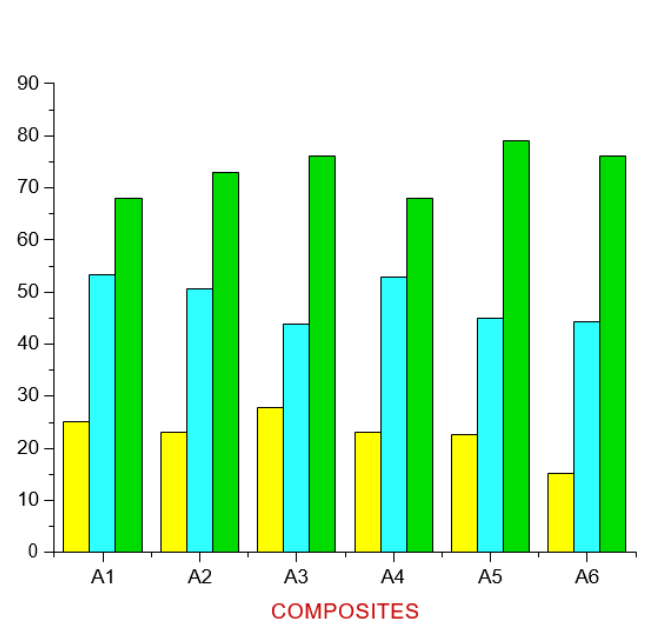

TS- Tensile Strength, FS- Flexural Strength, H- Shore D Hardness

Figure 4. Mechanical properties of group-A composite materials

\subsection{Flexural strength}

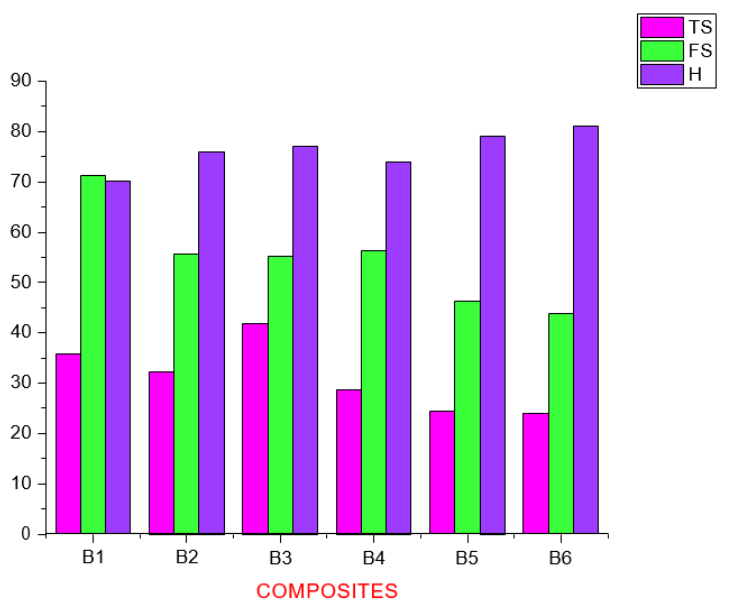

TS- Tensile Strength, FS- Flexural Strength, H- Shore D Hardness

Figure 5. Mechanical properties of group-B composite materials
The variations of flexural strength of samples across group $\mathrm{A}$ and $\mathrm{B}$ are represented graphically in the Figures $4 \& 5$. The structural application and stability of the material is mainly based on the flexural strength of the material. The flexural strength increases with increase in $\mathrm{SiC}$ up to $6 \mathrm{wt} \%$ and further increase in $\mathrm{wt} \%$ of $\mathrm{SiC}$ reduces the flexural strength. The addition of $\mathrm{SiC}$ reduces the flexural strength in the both group A \& B composite samples. On the other hand, group B samples shows the increase in flexural strength with the addition of $\mathrm{SiC}$ up to $6 \%$ (samples B2 and B3) and further increase in $\mathrm{SiC}$ deteriorates the flexural strength. Anyhow, the maximum strength 71.17 Mpa was recorded with sample B1. The flexural strength of group B samples showed higher than the group A specimens at all combinations of fibers. The highest flexural strength in group A and B samples are $54.3 \mathrm{~N} / \mathrm{mm} 2$ and 71.2 $\mathrm{N} / \mathrm{mm}^{2}$ respectively. It indicates that the addition and reinforcement of sisal fiber increase the flexural strength of the composite by $30 \%$.

\subsection{Water absorption test}

The water absorption test is performed in accordance with standards ASTM D 570. Individual samples were kept for 120 $\mathrm{h}$ in a beaker filled with distilled water at room temperature, later the samples are removed from the beaker and completely wiped out and weighed using Shimadzu BL320H digital weighing scale with a precision of $0.001 \mathrm{~g}$.

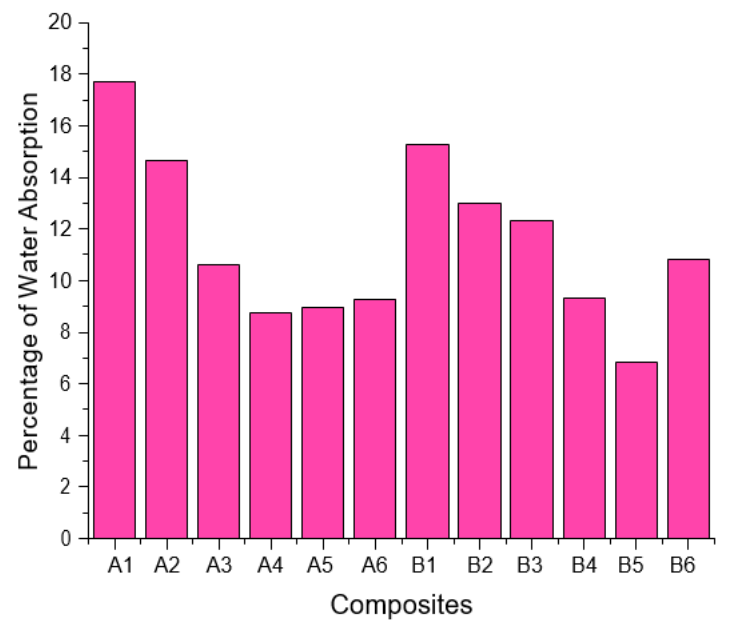

Figure 6. Water absorption behaviors of epoxy hybrid composites

Figure 6 shows high water absorption with $40 \%$ snake grass fiber and combination of $20 \%$ snake grass/ $20 \%$ sisal fiber content is observed for A1 and B1 samples. This is due to the hydrophilic nature of the fibers. The fibers contain free hydroxyl groups that can interact with water molecules by bonding with hydrogen and also the hollow tubular structure of the fibers allows water molecules to be diffused into composites. Samples A2- A6 shows decreasing in \% of water absorption due to reduction of fibers $w t \%$. Similarly for group B composites also showed improved water absorption property. B6 Sample with $10 \mathrm{wt} \%$ of SiC shows $10.81 \%$ water absorption this is due to the Voids or defects found in the matrix and at the fiber/matrix interface may also contribute to the penetration of water molecules into the composites. By contrast, with the addition of silicon carbide, the percentage of water absorption decreased drastically. This is because the silicon carbide particles are hydrophobic in nature. Thus 
Effect of Silicon Carbide on the Mechanical and Thermal Properties of Snake Grass/Sisal Fiber Reinforced Hybrid Epoxy Composites / J. New Mat. Electrochem. Systems

silicon carbide prevents water molecules from penetrating into the composites, reduces water absorption and also reduces the void content.

\subsection{Surface morphology}

In epoxy resin-based composites, the bonding property (fibre-resin interaction) is important to improve the mechanical properties such as tensile, impact and flexural strength. SEM micrographs show the uniform fiber and $\mathrm{SiC}$ distribution of the composites in the epoxy resin matrix. EDAX spectra analysis was carried out on each of the composites and the corresponding spectra are shown in Figure 7. Presence of various elements with wt $\%$ is shown in Table 4.
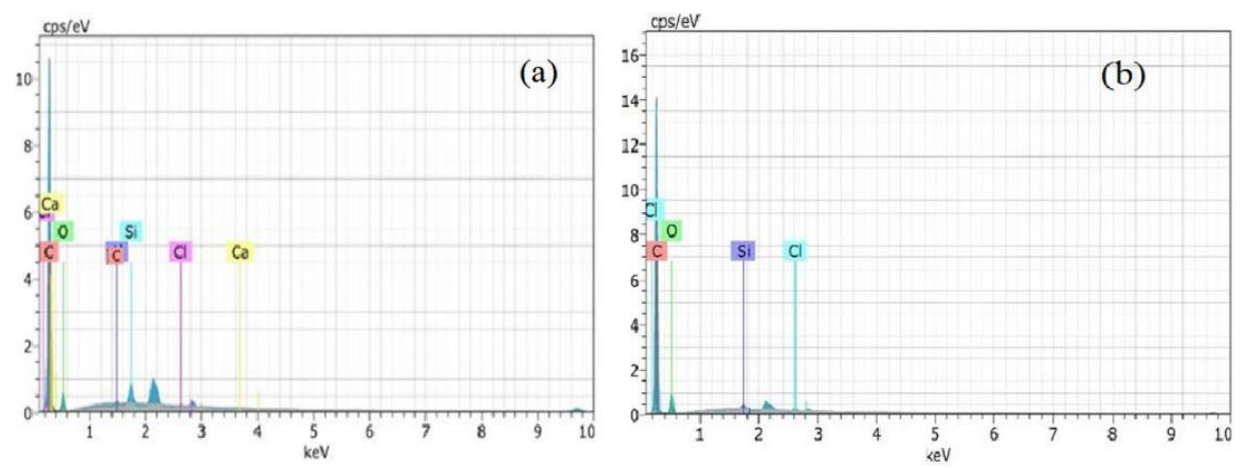

Figure 7. EDAX spectra (a) snake fiber composite (b) snake fiber and sisal fiber composite
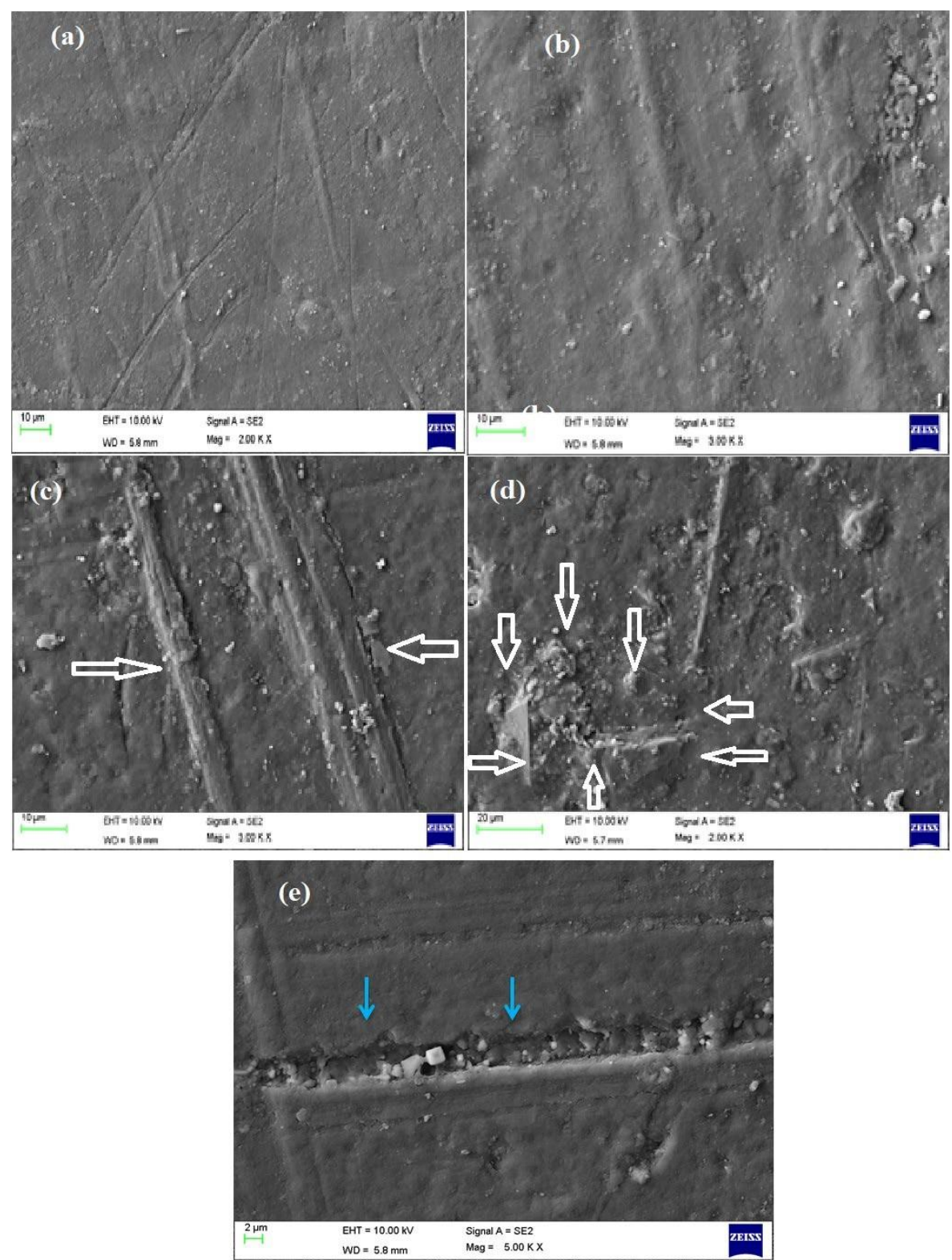

Figure 8. (a- e) SEM microstructure of of SGF/SiC/epoxy and SGF/SF/SiC/epoxy hybrid composites 
From Figure 8 (a-b), showed homogeneously dispersed fibers in the epoxy resin thus good adhesion between fibers and the matrix and void reduction certainly results in very high tensile strength upto addition $\mathrm{SiC} 8 \mathrm{wt} \%$ in the composites. But it doesn't affect the hardness of the composites. Concentration of $\mathrm{SiC}$ powders can be seen on the surface of the composites in higher $\mathrm{SiC} 10 \mathrm{wt} \%$, thus results in variation in the tensile and flexural strength of the composites, mechanical strength gradually improved by addition of fibers upto 40 as optimal wt $\%$.

Table 4. EDAX elemental concentrations (wt \%) of the selected areas in composites A \& B

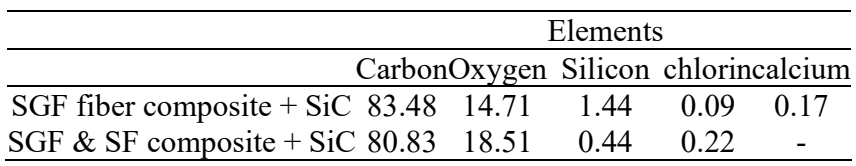

From Figure 8 (d) it is clear that the interfacial adhesion between the fibers, $\mathrm{SiC}$ and resin is poor in the $10 \mathrm{wt} \% \mathrm{SiC}$ composite. Indeed, the fibers are shown on the surface of the composite and voids presence reduces the tensile strength. The poor mechanical properties of hybrid composites at higher $\mathrm{SiC}$ content are due to the agglomeration of the $\mathrm{SiC}$ powder and improper bonding leads to fiber breakage by the application of the applied load and rich concentration of the $\mathrm{SiC}$ powder can be seen in B6 composites shown in Figure 8 (e).

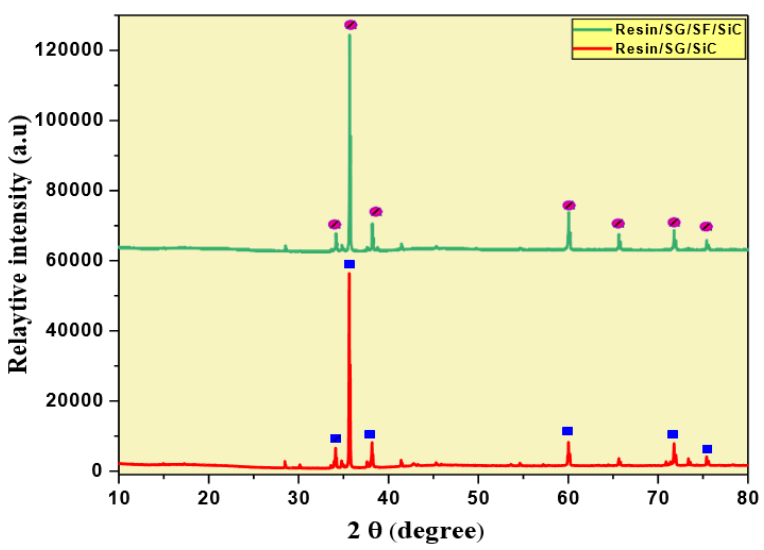

Figure 9. XRD patterns of fabricated composites i) A5$\mathrm{Resin} / \mathrm{SGF} / \mathrm{SiC}$ ii) B6- Resin/SGF/SF/SiC

XRD pattern of composites A5 and B6 are shown in Figure 9. The characteristic diffraction peaks of $\mathrm{SiC}$ particle $(2 \theta=$ $34.11^{\circ}, 35.63^{\circ}, 38.16^{\circ}, 60.2^{\circ}, 71.77^{\circ}$ and $\left.75.40^{\circ}\right)$ were assigned to the (101) (111), (103), (220), (311) and (222) reflections respectively [22]. From the XRD pattern of composites $\mathrm{SiC}$ shows sharp and well-defined peaks indicating the crystalline nature of $\mathrm{SiC}$, the observed $2 \theta$ values are compared with the standard JCPDS values (JCPDS No. 29-1129). Composites A5 and B6 are chemically identical, but the $\mathrm{SiC}$ particles are arranged differently. However the diffraction pattern of $\mathrm{B} 6$ composite is slightly varied as the $\mathrm{SiC}$ wt \% increased than the A5 composite. Since epoxy resin does not have crystal structure, the diffraction peak of epoxy resin cannot be detected by XRD.

\subsection{FTIR test analysis}

FTIR test was conducted on the 3rd type of composites in Group A and Group B composite structures because 3rd type composition structure possess good mechanical strength relatively compare than other types. The results of the FTIR test are shown in Figure 10. The FTIR spectra of A3 composite sample shows the peaks at 3734, 3608, 2987, 2308, 1693 and 1513 wavenumber $\mathrm{cm}^{-1}$.

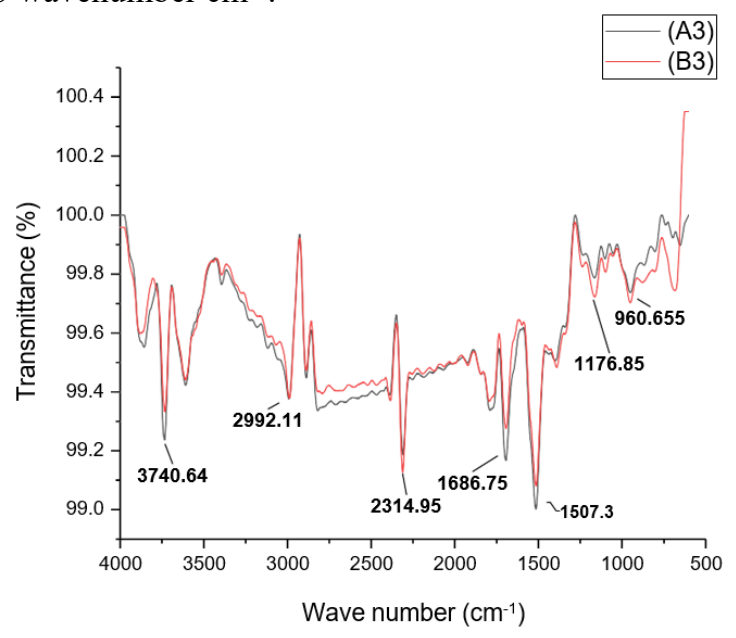

Figure 10. FTIR Spectroscopy of SGF/SiC/epoxy and $\mathrm{SGF} / \mathrm{SF} / \mathrm{SiC} /$ epoxy hybrid composites

The FTIR spectra of sample A3 shows the peaks at 3734, $3608,2987,2308,1693$ and 1513. The peaks in the spectra of sample B3 is also very close to the same wave numbers. These peaks at 3734 and 3608 belong to $\mathrm{O}-\mathrm{H}$ groups of carboxylic acid due to the cellulose. The peak at 2987 indicates the presence of aliphatic compound $(\mathrm{C}-\mathrm{H})$. Since, there is a peak at 1513 indicates that the possibility of linear chain of aliphatic compound. The peaks at 2308 might be the indication of presence of triple bond between carbon molecules [23]. A normal or moderate absorption at 1693 shows the carboxyl stretching of C-O, is a hemicelluloses of acetyl group. Lesser hemicelluloses is indicated by small absorption peaks which is advantageous as it deteriorates the mechanical properties [24].

\subsection{Thermal property analysis}

Thermogravimetric analysis (TG) and differential scanning calorimeter (DSC) analysis

The thermal behaviors of Snake Grass fiber (SGF) composite and Snake Grass fiber (SGF) combined with Sisal Fiber (SF) composites were analyzed by TG and DSC curves in the nitrogen atmosphere.

Figure 11(i) \& 12(i) shows the TG curves of $w t \%$ of $\mathrm{SGF} / \mathrm{SiC} / \mathrm{epoxy}$ and $\mathrm{wt} \%$ of $\mathrm{SGF} / \mathrm{SF} / \mathrm{SiC}$ epoxy matrix composites. Sisal fiber reinforced composites (SGF/SF/SiC/epoxy) had much higher thermal stability than snake grass and $\mathrm{SiC}$ reinforced composite.

Table 5. Measurement of thermal degradation temperature of hybrid composites

\begin{tabular}{cccccc}
\hline Sample & $\mathrm{T} 10 \%\left({ }^{\circ} \mathrm{C}\right) \mathrm{T} 50 \%\left({ }^{\circ} \mathrm{C}\right) \mathrm{T} 70 \%\left({ }^{\circ} \mathrm{C}\right) \mathrm{Tmax}\left({ }^{\circ} \mathrm{C}\right) \mathrm{R} 547$ \\
\hline SGF/SiC/epoxy & 310 & 368 & 399 & 464 & 17 \\
SGF/SF/SiC/epoxy & 323 & 388 & 404 & 479 & 29 \\
\hline
\end{tabular}

T10\%- 10\% weight loss temperature., T50\%-50\% weight 
loss temperature., $\mathrm{T} 70 \%-70 \%$ weight loss temperature., Tmax-final degradation temperature, R547 -Residue weight $(\%)$ at $547^{\circ} \mathrm{C}$.

Table 5 shows Initial degradation temperatures of the $\mathrm{SGF} / \mathrm{SiC} /$ epoxy (A5) and SGF/SF/SiC/epoxy (B6) composites are $310^{\circ} \mathrm{C}$ and $323^{\circ} \mathrm{C}$ respectively with mass loss of $10 \%$ in both the composites. There is a slight variation in degradation of the composites at initial stage. $50 \%$ of mass loss of the A5 and $\mathrm{B} 6$ composites occurred at the temperature of $368^{\circ} \mathrm{C}$ and $388^{\circ} \mathrm{C}$ respectively. This is due to the influence of $\mathrm{SiC}$ in the composite. The fiber absorbs water due to its hydrophilic nature and the loss of absorbed water interrupts the thermogram at $40^{\circ} \mathrm{C}-100^{\circ} \mathrm{C}$. This phenomenon was found in the fibers which contains $\mathrm{O}-\mathrm{H}$ functional groups. The negligible amount of mass percentage of fiber was observed in the range of $60^{\circ} \mathrm{C}-300^{\circ} \mathrm{C}$ due to the lower rate of degradation of fiber at this temperature range. After $300^{\circ} \mathrm{C}$, the degradation of lignin, cellulose, and hemicelluloses present in the fiber was more rapid and major weight loss was observed [25].

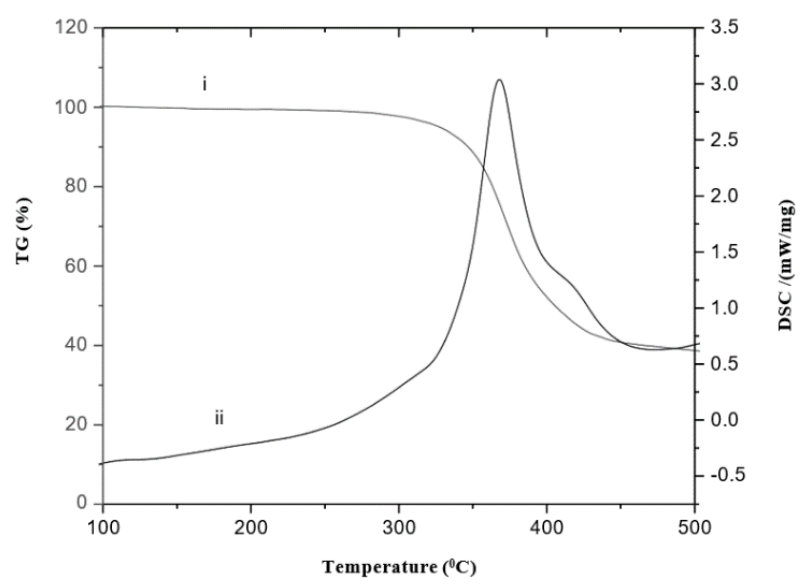

Figure 11. TG (i) and DSC (ii) curves of of SGF/SiC/epoxy hybrid composites

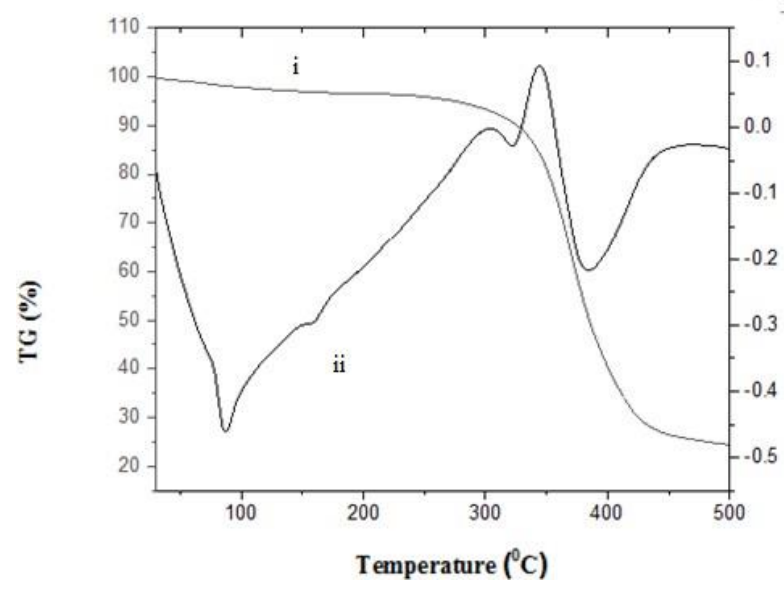

Figure 12. TG (i) and DSC (ii) curves of of $\mathrm{SGF} / \mathrm{SF} / \mathrm{SiC} / \mathrm{epoxy}$ hybrid composites

Major mass loss $(70 \%)$ occurred at almost at the same temperature $399^{\circ} \mathrm{C}$ and $404^{\circ} \mathrm{C}$ respectively. Maximum degradation temperature is $463.943^{\circ} \mathrm{C}$ and $478.943^{\circ} \mathrm{C}$ in $\mathrm{A} 5$ and $\mathrm{B} 6$ composites. By increasing the weight percentage of $\mathrm{SiC}$ substance degradation temperature of the composites increased. At $548^{\circ} \mathrm{C}$, group A composite leaves $17 \%$ of residual mass whereas group B sample leaves $29 \%$. B6 showed high thermal stability due to the sisal fiber wt $\%$ and increased $\mathrm{wt} \%$ of the $\mathrm{SiC}$. From the TGA results similar degradation pattern was found in both the composites. But, the reduction in mass percentage in the temperature band is comparatively less and is slow in the B6 composite.

Figure 11 (ii) shows the DSC curve in nitrogen atmosphere of SGF/SiC/epoxy hybrid composite. It has peaks of it major constituents namely cellulose, hemicelluloses and lignin. The corresponding exothermic peak starts at $340^{\circ} \mathrm{C}$ and maximum at $380^{\circ} \mathrm{C}$ as the hemicelluloses i.e. acetyl 4-o methyl glucuronoxylan present in the snake fiber was degrade [24, 26]. Another very small endothermic zone at $420^{\circ} \mathrm{C}$ indicates the degradation of its major constituent cellulose. This peak indicates depolymerization of cellulose and dehydration leads the formation of flammable volatile products [27].

The DSC curve for the SGF/SF/SiC/epoxy hybrid composite was presented in Figure 12 (ii). The exothermic peak was found at $300^{\circ} \mathrm{C}$ due to the loss of hemicelluloses of snake fiber and at $345^{\circ} \mathrm{C}$ a small peak indicates the loss of hemicelluloses of sisal fiber. Another endothermic peak at $380^{\circ} \mathrm{C}$ due to the degradation of cellulose present in the fiber of the composite. The results of TG and DSC test show that snake and sisal fiber composite has higher temperature of degradation than the snake grass fiber composite.

\section{CONCLUSIONS}

Convincingly, the present work clearly shows that the Snake Grass (SGF) fiber and Sisal fiber (SF) will become a future alternative for the conventional materials due to its enhanced mechanical properties and availability. The following conclusions are made based on the comprehensive experimental study.

1. The tensile and flexural properties of SGF/SF/SiC/epoxy hybrid composites are 14.08 MPa and 3.52 MPa higher than the SGF/SiC/epoxy hybrid composites. Tensile strength of both groups of composites are increased with $\mathrm{SiC}$ up to $6 \%$ and then decreased. In B1 composite sample addition of sisal fiber with snake grass fiber increases the tensile strength about 10.47 $\mathrm{MPa}$ and 17.4 $\mathrm{MPa}$ in flexural strength than A1 composite. (B1>A1)

2. Addition of $\mathrm{SiC}$ in the matrix increases the shore $\mathrm{D}$ hardness in both the composites. Snake grass (SGF) and Sisal (SF) fibers wt \% also greatly influenced in the shore $\mathrm{D}$ hardness of the Composites. Maximum of 81 shore D hardness was achieved with $10 \mathrm{wt} \%$ of $\mathrm{SiC}$ in group-B composite.

3. High water absorption is due to the hydrophilic nature of the fibers. By contrast, with the addition of silicon carbide, the percentage of water absorption decreased drastically. This is because the silicon carbide particles are hydrophobic in nature. Thermal stability of composites increased due to the inclusion of silicon carbide particles.

4. Degradation of water occurs in the same temperature range in both composites and degradation of the constituents of snake and sisal fiber takes place at little higher temperature than snake fiber composite. The addition of SiC particles in the epoxy matrix is one of the suitable methods of improving thermal stability of nature fiber composites. The composites obtained are costeffective, lightweight and environmentally friendly. 


\section{REFERENCES}

[1] Gholampour, A., Ozbakkaloglu, T., Journal of Materials Science, 55(3), 829 (2020). https://doi.org/10.1007/s10853-019-03990-y

[2] Sathishkumar, T.P., Navaneethakrishnan, P., Shankar, O., Composites Science and Technology, 72(10), 1183 (2012). https://doi.org/10.1016/j.compscitech.2012.04.001

[3] Ganeshan, P., Kumaran, S.S., Raja, K., Venkateswarlu, D., Materials Research Express, 6(1), 015303 (2018). https://doi.org/10.1088/2053-1591

[4] de Andrade Silva, F., Chawla, N., de Toledo Filho, R.D., Composites Science and Technology, 68(15-16), 3438(2008). https://doi.org/10.1016/j.compscitech.2008.10.001

[5] Sathish, S., Kumaresan, K., Prabhu, L., Vigneshkumar, N., Polymers and Polymer Composites, 25(3), 229 (2017). https://doi.org/10.1177/096739111702500309

[6] Latif, R., Wakeel, S., Zaman Khan, N., Noor Siddiquee, A., Lal Verma, S., Akhtar Khan, Z., Journal of Reinforced Plastics and Composites, 38(1), 15 (2019). https://doi.org/10.1177/0731684418802022

[7] Bakare, I.O., Okieimen, F.E., Pavithran, C., Khalil, H.A., Brahmakumar, M., Materials \& Design, 31(9), 4274 (2010). https://doi.org/10.1016/j.matdes.2010.04.013

[8] Li, Y., Hu, C., Yu, Y. (2008). Interfacial studies of sisal fiber reinforced high density polyethylene (HDPE) composites. Composites Part A: Applied Science and Manufacturing, 39(4): 570-578. https://doi.org/10.1016/j.compositesa.2007.07.005

[9] Rong, M.Z., Zhang, M.Q., Liu, Y., Yang, G.C., Zeng, H.M., Composites Science and technology, 61(10), 1437 (2001). https://doi.org/10.1016/S0266-3538(01)00046-X

[10] Sathishkumar, T.P., Navaneethakrishnan, P., Shankar, S., Kumar, J., Journal of composite materials, 47(18), 2181(2013). https://doi.org/10.1177/0021998312454903

[11] Sathishkumar, T.P., Naveen, J.A., Satheeshkumar, S., Journal of Reinforced Plastics and Composites, 33(5), 454 (2014). https://doi.org/10.1177/0731684413516393

[12] Ganapathy, T., Sathiskumar, R., Sanjay, M.R., Senthamaraikannan, P., Saravanakumar, S.S., Parameswaranpillai, J., Siengchin, S., Journal of Natural Fibers, 1-8 (2019). https://doi.org/10.1080/15440478.2019.1675219

[13] Sathish, S., Kumaresan, K., Prabhu, L., Gokulkumar, S., Revista Romana de Materiale, 48(4), 476 (2018).

[14] Nhuapeng, W., Thamjaree, W., Kumfu, S., Singjai, P., Tunkasiri, T., Current Applied Physics, 8(3-4), 295 (2008). https://doi.org/10.1016/j.cap.2007.10.074
[15] Rambabu, V., Naidu, A.L., Kona, S., In Recent Advances in Material Sciences, 17-26 (2019). https://doi.org/10.1007/978981-13-7643-6_2

[16] George, J., Verpoest, J.I., Die Angewandte Makromolekulare Chemie, 272(1), 41 (1999).

https://doi.org/10.1002/(SICI)15229505(19991201)272:1<41:: AID-APMC41>3.0.CO;2-X

[17] Van de Velde, K., Baetens, E., Macromolecular Materials and Engineering, 286(6), 342 (2001). https://doi.org/10.1002/14392054(20010601)286:6<342::AID-MAME342>3.0.CO;2-P

[18] Loganathan, M., Dinesh, S., Vijayan, V., Ranjithkumar, M., Rajkumar, S., Journal of New Materials for Electrochemical Systems, 23(1): 40 (2020). https://doi.org/10.14447/jnmes.v23i1.a08

[19] Loganathan, M., Dinesh, S., Vijayan, V., Karuppusamy, T., Rajkumar, S., Journal of New Materials for Electrochemical Systems, 23(1), 36 (2020). https://doi.org/10.14447/jnmes.v23i1.a07

[20] Sreekumar, P.A., Saiah, R., Saiter, J.M., Leblanc, N., Joseph, K., Unnikrishnan, G., Thomas, S., Composite interfaces, 15(6), 629 (2008). https://doi.org/10.1163/156855408785971317

[21] Martin, A.R., Martins, M.A., da Silva, O.R., Mattoso, L.H., Thermochimica Acta, 506(1-2), 14 (2010). https://doi.org/10.1016/j.tca.2010.04.008

[22] Shen, D., Zhan, Z., Liu, Z., Cao, Y., Zhou, L., Liu, Y., Yu, J., Scientific reports, 7(1), 1 (2017). https://doi.org/10.1038/s41598-017-02929-0

[23] Creton, B., Bougeard, D., Smirnov, K.S., Guilment, J., Poncelet, O., Physical Chemistry Chemical Physics, 10(32), 4879 (2008). https://doi.org/10.1039/B803479F

[24] Indran, S., Raj, R.E., Sreenivasan, V.S., Carbohydrate Polymers, 110, 423 (2014). https://doi.org/10.1016/j.carbpol.2014.04.051

[25] Anidha, S., Latha, N., Muthukkumar, M., Journal of Materials Research and Technology, 9(4), 7947 (2020). https://doi.org/10.1016/j.jmrt.2020.04.081

[26] Bradbury, A.G., Sakai, Y., Shafizadeh, F., Journal of applied polymer science, 23(11): 3271 (1979). https://doi.org/10.1002/app.1979.070231112

[27] Prasad, V., Joseph, M.A., Sekar, K., Composites part A: Applied science and manufacturing, 115, 360 (2018). https://doi.org/10.1016/j.compositesa.2018.09.031

[28] Rajaguru, K., Vijayan, V., Saravanan, S., Antony, A.G., International Journal of Vehicle Structures \& Systems, 11(4), 422 (2019). https://doi.org/10.4273/ijvss.11.4.16 